\title{
ANXIETY, DEPRESSION AND INSOMNIA CONDITIONS IN ITALIAN NURSES DURING THE FIRST AND THE SECOND WAVES OF THE COVID-19 PANDEMIC
}

$\frac{\text { Elsa Vitale } * 1}{{ }^{1} \text { Mental Health Center Modugno (Bari), Local Healthcare Company Bari, Italy. }}$

\begin{abstract}
Background: To assess the levels of anxiety, depression and insomnia among Italian nurses directly involved in the care of patients with Covid-19, considering the first and the second wave of the pandemic.

Methods: An online questionnaire was administered on some pages of the nursing social networks and addressed precisely to nurses directly involved in the care of patients affected by Covid-19 in two different periods of the pandemic: during the first wave (March2020 - May 2020) and during the second wave (October 2020 - November 2020).

Results: A total of 592 nurses agreed to participate in the study: 291 nurses during the first wave and 301 during the second wave. No significant differences were recorded among the two groups based on anxiety disorder $(p=.364)$. A significant difference between the two groups were recorded considering the depression and the insomnia condition, too $(\mathrm{p}<.001$; $\mathrm{p}<.001$ ). Additionally, no significant differences were recorded between the two waves, both for the anxiety, depression and insomnia disorders. In fact, there were only sex-related differences for each wave, but between the two waves the condition among nurses did not vary significantly.

Conclusion: Further psychological support should be implemented and nurses encouraged in their care of patients suffered from Covid-19.
\end{abstract}

Keywords: Anxiety-Covid-19-Pandemic-Depression-Insomnia-Nurses

\section{Introduction}

Starting from December 2019 a new SARS-CoV-2 infection rapidly spread all over the world, assuming the pandemic condition from March 2020 (World Health Organization, 2020). During all this period, nurses were playing an

\footnotetext{
* Correspondence concerning this article should be addressed to Elsa Vitale, Department of Mental Health, Local Healthcare Company Bari, Italy, Via X marzo, 43, 70026 Modugno, Bari.

E-mail: vitaleelsa@libero.it
} 
extraordinary role in the fight against Covid-19: they concentrated all their achievements hazarding their lives in emergency wards, infection control units, intensive care units and hospital wards (Catton, 2020). In Wuhan, where the pandemic has begun, and then all over the world, nurses strained with extreme work, insufficient supplies, confusion, stress and fear levels, due to the high contagiousness and danger of the infection (Velavan et al., 2020; Vitale et al., 2020).

Moreover, during the pandemic, nurses lived also isolated, working in highrisk areas, and providing care to infected people can cause traumatic effects in the future (Kang et al. 2020b). High-stress emotional and psychological problems adversely affect nurses' future cognitive functions and clinical decision-making processes. Nurses were constantly faced with stressful situations that caused emotional exhaustion as they managed complex care and treatment processes (Moitra et al., 2021). Particularly during the Covid-19 pandemic, working for long periods in an environment with a high level of stress and uncertainty, relocating nursing units or wards, and increasing workload, nurses were found to experience burnout more rapidly (Drennan et al., 2019; Vitale et al., 2020). Already literature reported even before the pandemic a high level of burnout among nurses, especially among those who worked in intensive care units. Furthermore, the incompatibility between the ideal expectations of the nursing profession and the situations encountered in real life also leads to burnout (Woo et al. 2020). However, this condition get worse during the pandemic, due to uncertainty and intense work that could be also associated to insomnia and depressive symptoms (Pappa et al. 2020; Badahdah et al. 2020). Nurses suffering from burnout might exhibit depressive and stressful symptoms, insomnia and problems with concentration and memory, which were very important in clinical units (Pradas - Hernández et al. 2018). All of these highly stressful situations for nurses could adversely affect their cognitive functions as well as their ability to make clinical decision-making, as they were constantly faced with stressful situations that caused emotional exhaustion and at the same time managed complex care and treatment processes. In particular, during the Covid-19 pandemic, nurses working with an increased workload, characterized by a high level of stress and uncertainty, very often finding the incompatibility between the ideal expectations of the nursing profession and the situations encountered in life royals experienced burnout more quickly (Drennan and Ross, 2019; Woo et al. 2020). The literature reported how nurses suffering from burnout could also show depressive and stressful symptoms, insomnia and problems with concentration and memory (Pradas - Hernández et al. 2018). As this regard, worldwide literature, from Hong Kong (Cheng et al., 2020) to China (Hu et al., 2020), from Germany (Bohlken et al., 2020) to Italy (Vitale et al., 2020; Ambrosi et al., 2020), agreed to consider high prevalence rates of anxiety, depression and insomnia among nurses during the Covid-19 pandemic. For example, in the Chinese study (Lai et al. 2020), the 
depression rate in health care workers was $50 \%$, anxiety $45 \%$ and insomnia $34 \%$. Also in the study of Badahdah et al. (2020), the severe anxiety rate was $25.9 \%$ and high stress was 56.4\%; and in the study of Kang et al. (2020), 36.9\% of 994 healthcare workers reported mental health disorders, too (Kang et al. 2020; Xiang et al. 2020).

Aim

Having been the pandemic characterized by two waves and, in some countries, in these days it is even reaching the third one, where there were peaks in the number of SARS-CoV-2 infections, the present study was designed to try to understand whether the levels of anxiety, depression and insomnia among Italian nurses directly involved in the care of patients suffered from the Covid-19 changed during the two Italian epidemic waves or remained the same.

\section{Materials and methods}

\section{Participants}

All Italian nurses directly involved in the care of Covid-19 patients in both the first (March 2020 - May 2020) and the second waves (October 2020 - November 2020) of the pandemic could participate in the study.

All data collected were treated guaranteeing the absolute anonymity of the information collected without any provision for a return of the data obtained and subsequently processed.

Procedure

An online questionnaire was created and published on some pages of the nursing social networks in order to publicize as much as possible the dissemination of the survey among Italian nurses.

The present study was presented and accepted by the Ethics Committee of the Policlinic of Bari Hospital, Italy, with ID number 6404/2020.

\section{Instruments}

The questionnaire collected information relating to: sex, whether female or male, confirming that the nurse interviewed was working in a Covid-19 ward. Then, the Generalized Anxiety Disorder, version 7 (GAD-7) (Spitzer et al., 2006), the 
Patient Health Questionnaire, version 9 (PHQ-9) (Kroenke et al., 2001) and the Insomnia Severity Index (ISI) (Bastien et al., 2001) were proposed in order to evaluate the anxiety, depression and insomnia conditions among Italian nurses, both in the first and in the second waves.

Specifically, the GAD-7 questionnaire assessed whether or not a generalized anxiety disorder occurred. It consisted of 20 multiple choice questions to which was associated a Linkert scale with values ranging from 1, as "almost never", to 4 , as "almost always". The sum of the values obtained from the different items, also considering the values attributed to the reverse items, provided a raw value to which a fixed factor equal to 1.25 was multiplied. The value obtained if it was lower than the reference value of 58.7 identified the absence of an anxiety disorder. Conversely, if the value obtained exceeded 58.7, a generalized anxiety disorder condition was diagnosed.

The PHQ-9 assessed a depression condition. It was made up of 9 multiple choice items, whose answers were associated with a value of the Linkert scale ranging from 0 , as: "no" or "not at all" to 4, as: "very serious". The sum of the scores obtained identified a condition, as: the absence of depression for total scores from zero to 4; the sub-clinical depression for scores between 5 and 9; the mild depression condition for scores between 10 and 14; the moderate depression for scores between 15 and 19 and finally, the severe depression condition for scores higher than 20.

The ISI questionnaire identified the insomnia condition. It consisted of 7 multiple choice items. Each response was associated with a value of the Linkert scale that varied from zero to 4 . The sum of the scores of each items provided a total value which identified an insomnia disorder, specifically, for values between zero and 7 : the absence of insomnia, for values between 8 and 14: the subclinical insomnia, for values between 15 and 21: the moderate insomnia; for values between 22 and 28: the severe insomnia.

\section{Validity and Reliability}

In this study it was adopted three homogenous instruments to assess anxiety, depression and insomnia levels among Italian nurses during the first and the second waves. The sensitivity and the specificity of these evaluation scales, as well as their reproducibility, have already been amply highlighted in previous evidence. Specifically, the GAD-7 Scale was an easy-self-report measure to assess generalized anxiety disorder symptoms. Literature reported good internal consistency and convergent validity (Kertz et al., 2013; Spitzer et al., 2006). However, the PHQ-9 was used to diagnose depressive disorders. Several studies had already tested its validity and reliability (Kroenke et al., 2012; Manea et al., 2012). Also it could be adopted in routine practice, within a variety of settings (Manea et al., 2015; Gilbody et al., 2007). Finally, the ISI score was a self-reporting scale that included two of the 
most common complaints about insomnia: difficulty initiating sleep and frequent awakenings from sleep (Veqar et al., 2017; Chahoud et al., 2017). This scale was widely validated for a number of age groups, and was reported to be a valuable assessment instrument for individuals with several disorders. The ISI has been translated into several languages, and demonstrated adequate psychometric properties (Fernandez-Mendoza et al., 2012; Lahan et al., 2011; Yu, 2010).

\section{Data Assessment}

Data were collected and sorted into an Excel spreadsheet and processed with IBM's SPSS software, version 20. All data collected were presented in frequencies and percentages. The chi-square test was performed to evaluate the differences obtained in the first and the second waves' groups. Then, also differences between female and male nurses were assessed by the chi-square test. Subsequently, the multivariate analysis of the data was performed in order to assess differences among nurses according to sex and the two waves of the Covid-19 pandemic. All significance values below 0.05 were evaluated as statistically significant.

\section{Results}

A total of 592 nurses involved in the care of Covid-19 patients agreed to participate in this survey (Table 1). Specifically, 291 (49.15\%) nurses participated during the first wave and 301 (50.85\%) during the second wave, respectively. No statistically significant differences were recorded according to $\operatorname{sex}(\mathrm{p}=.225)$ and to the presence of a generalized anxiety disorder $(\mathrm{p}=.364)$. In fact, the two groups appeared mostly homogeneous: there was a clear prevalence of the female component in the two samples (35.98\% in the first wave group; $50.85 \%$ in the second wave group, respectively) and most of the participants, both for the first and the second wave groups, did not reported a generalized anxiety disorder, $(35.98 \%$ in the first wave group; $35.47 \%$ in the second wave group, respectively). As regards the depression condition, there was a significant difference between the two groups $(p<.001)$ : the second wave group reported a higher frequency in depressive disorder than the first wave group. In fact, the $2.19 \%$ of the first wave group recorded a subthreshold depression level versus the $11.65 \%$ of the second wave group. Moreover, the $9.46 \%$ of the first wave group reported a mild depressive condition versus the $12.33 \%$ of the second wave group. Additionally, the $3.38 \%$ of the first wave group recorded a moderate depressive disorder versus the $12.5 \%$ in the second wave group and finally, as regards the severe depressive conditions, the first wave group did not record any case versus the $7.77 \%$ of the second wave. 
Finally, as regards the insomnia conditions, there was a significant difference between the values recorded, in fact during the first wave nurses recorded higher moderate and severe insomnia levels than the second Wave group $(p<.001)$.

Table 1. Sampling characteristics of Italian nurses during the First and the Second Waves of the Covid-19 outbreak ( $\mathrm{n}=592)$.

\begin{tabular}{llll}
\hline \multicolumn{1}{c}{ Variable } & $\begin{array}{c}\text { First Wave } \\
(\mathbf{n = 2 9 1 ; 4 9 . 1 5 \% )} \mathbf{n}(\mathbf{\%})\end{array}$ & $\begin{array}{c}\text { Second Wave } \\
(\mathbf{n}=\mathbf{3 0 1 ; 5 0 . 8 5 \% )} \mathbf{n}(\mathbf{\%})\end{array}$ & p value \\
\hline Sex & $213(35.98 \%)$ & $234(39.53 \%)$ & .215 \\
Female & $78(13.17 \%)$ & $67(11.32 \%)$ & \\
Male & & & \\
\hline GAD-7 & $78(13.17 \%)$ & $91(15.37 \%)$ & .364 \\
Yes & $213(35.98 \%)$ & $210(35.47 \%)$ & $<.001^{*}$ \\
No & & & \\
\hline PHQ-9 & $82(13.85 \%)$ & $39(6.58 \%)$ & \\
Absent & $133(2.19 \%)$ & $69(11.65 \%)$ & \\
Sub-threshold depression & $56(9.46 \%)$ & $73(12.33 \%)$ & \\
Mild major depression & $20(3.38 \%)$ & $74(12.5 \%)$ & \\
Moderate major depression & $0(0 \%)$ & $46(7.77 \%)$ & \\
Severe major depression & & & \\
\hline ISI & $65(10.98 \%)$ & $78(13.17 \%)$ & \\
No clinically significant & $91(15.37 \%)$ & $124(20.95 \%)$ & \\
Subthreshold & $102(17.23 \%)$ & $92(15.54 \%)$ & \\
Moderate & $33(5.57 \%)$ & $7(1.18 \%)$ & \\
Severe & & & \\
\hline
\end{tabular}

Abbreviations: GAD-7: Generalized Anxiety Disorder- 7; PHQ-9: Patient Health Questionnaire-9; ISI: Insomnia Severity Index.

Note: ${ }^{*} \mathrm{p}<0.05$ is statistically significant.

Table 2 showed the differences according to sex both in the first and second wave and between the two pandemic waves, respectively. During the first wave there was no significant difference $(\mathrm{p}=.655)$ between the presence of an anxiety disorder between females $(9.97 \%)$ and males (3.21\%); while during the second wave there was a significant increase $(\mathrm{p}=.005)$ in the number of females $(13.51 \%)$ who reported an anxiety disorder than males $(1.86 \%)$. On the other hand, no significant difference was assessed among females and males during the first and in the second waves $(\mathrm{p}=.091)$.

As regards depression conditions, data evidenced a significant difference among females and males during the first wave $(p=.023)$ : more females recorded depression conditions than males (sub-threshold: $16.89 \%$ females vs $5.57 \%$ males; mild: $7.43 \%$ females vs $2.03 \%$ males; moderate: $3.04 \%$ females vs $0.34 \%$ males). The same trend was found during the second wave $(\mathrm{p}=.023)$, in which nurses registered also severe depressive condition, too ( $6.42 \%$ females; $1.35 \%$ males). However, differences among females and males during the first and the second waves were not statistically significant $(\mathrm{p}=.188)$. 
Finally, as regards the insomnia condition, there was a significant difference between females and males $(\mathrm{p}=.029)$ during the first wave: more females recorded sub-threshold, moderate and severe insomnia conditions $(11.15 \%, 13.51 \%, 4.73 \%$, respectively) than males $(4.22 \%, 3.73 \%, 0.84 \%$, respectively). However, during the second wave, there were no significant differences among females and males in insomnia levels $(\mathrm{p}=.392)$. Also between the first and the second wave there were no significant difference among female and male nurses $(\mathrm{p}=.396)$.

Table 2. Differences among Anxiety, Depression and Insomnia levels in Italian Nurses during the First and the Second Waves according to sex

\begin{tabular}{|c|c|c|c|c|c|c|c|c|}
\hline \multirow{2}{*}{$\begin{array}{c}\begin{array}{c}\text { Psychological } \\
\text { conditions }\end{array} \\
\end{array}$} & \multicolumn{2}{|c|}{ First Wave } & \multirow[t]{2}{*}{ pvalue $^{a}$} & \multicolumn{2}{|c|}{ Second Wave } & \multirow[t]{2}{*}{ pvalue $^{a}$} & \multirow[t]{2}{*}{$\mathbf{F}$} & \multirow[t]{2}{*}{ pvalue $^{\text {b }}$} \\
\hline & Female & Male & & Female & Male & & & \\
\hline \multicolumn{9}{|l|}{ GAD-7 } \\
\hline Yes & $59(9.97 \%)$ & $19(3.21 \%)$ & .655 & $80(13.51 \%)$ & $11(1.86 \%)$ & $.005 *$ & 2.805 & .091 \\
\hline No & $154(26.01 \%)$ & $59(9.97 \%)$ & & $154(26.01 \%)$ & $56(9.46 \%)$ & & & \\
\hline \multicolumn{9}{|l|}{ PHQ-9 } \\
\hline Absent & $51(8.61 \%)$ & $31(5.24 \%)$ & $.023 *$ & $24(4.05 \%)$ & $15(2.53 \%)$ & $.023 *$ & 1.735 & .188 \\
\hline Sub-threshold & $100(16.89 \%)$ & $33(5.57 \%)$ & & $49(8.28 \%)$ & $20(3.38 \%)$ & & & \\
\hline Mild major & $44(7.43 \%)$ & $12(2.03 \%)$ & & $61(10.30 \%)$ & $12(2.03 \%)$ & & & \\
\hline Moderate & $18(3.04 \%)$ & $2(0.34 \%)$ & & $62(15.82 \%)$ & $12(2.03 \%)$ & & & \\
\hline major & $0(0 \%)$ & $0(0 \%)$ & & $38(6.42 \%)$ & $8(1.35 \%)$ & & & \\
\hline \multicolumn{9}{|l|}{ Severe major } \\
\hline ISI & & & & & & & & \\
\hline Absent & $65(10.98 \%)$ & $26(4.39 \%)$ & $.029 *$ & $58(9.80 \%)$ & $20(3.38 \%)$ & .392 & .722 & .396 \\
\hline Sub-threshold & $66(11.15 \%)$ & $25(4.22 \%)$ & & $95(16.05 \%)$ & $29(4.90 \%)$ & & & \\
\hline Moderate & $80(13.51 \%)$ & $22(3.73 \%)$ & & $74(12.50 \%)$ & $18(3.04 \%)$ & & & \\
\hline Severe & $28(4.73 \%)$ & $5(0.84 \%)$ & & $7(1.18 \%)$ & $0(0 \%)$ & & & \\
\hline
\end{tabular}

Abbreviations: GAD-7: Generalized Anxiety Disorder- 7; PHQ-9: Patient Health Questionnaire-9; ISI: Insomnia Severity Index.

Note: ${ }^{*} \mathrm{p}<0.05$ is statistically significant; a: chi square test; b: multivariate analyses test.

\section{Discussion}

The purpose of the present study was to highlight any differences between the conditions of anxiety, depression and insomnia levels among the Italian nurses directly involved in the care of Covid-19 patients during the first and the second wave of the pandemic. Considering greater exposure to the adversity dictated by the pandemic, the expectation of the results included a worsening of the mental health conditions of the nurses during the second wave. On the contrary, the data did not confirm this hypothesis: during the first wave there was no significant difference between the number of female and male nurses with or without anxiety disorders $(\mathrm{p}=.655)$. On the other hand, during the second wave there was a significant difference $(p=.005)$ between the number of female and male nurses with an increase in the number of female nurses with anxiety disorders (13.51\%). However, 
considering the difference between the two waves, there was no significant difference between the first and the second waves considering the number of female and male nurses with or without anxiety disorders $(\mathrm{p}=.091)$. Conversely, as regards the depressive condition there were significant worsening during both the first $(p=.023)$ and the second wave $(p=.023)$ between females and males. Particularly, during the second wave, more female nurses recorded moderate and severe depression condition than males. Finally, as regards the insomnia condition, during the first wave more females significantly recorded insomnia disorders than males $(p=.029)$. While during the second wave there were no significantly differences among females and males $(\mathrm{p}=.392)$ and also by considering the two waves, too $(\mathrm{p}=.396)$.

Therefore, from the data obtained it could be deduced that no significant differences were recorded between the two waves, both for the anxiety, depression and insomnia disorders. In fact, there were only sex-related differences for each wave, but between the two waves the condition among nurses did not vary significantly. In any case, data were more encouraging for anxiety disorders where most of the interviewees did not present any disturbance, while for depressive disorders the situation during the second wave was worse: the number of nurses with moderate and severe depression increased. While insomnia disorders showed an inverse trend, registering a greater number of disorders during the first wave, compared to the second.

Although the literature reported an increase in the incidence of anxiety cases at the onset of maxi-health emergencies related to lack of information on the health condition, fear of getting infected, prolonged exposure to long and tiring work shifts (Salari et al., 2020; Wu et al., 2020), the data reported in this study instead showed a rather encouraging incidence of anxiety and conversely during the second wave a significant increase in the number of female nurses with an anxiety disorder. Therefore, the reported data could be considered in disagreement with what is exposed in the literature where, at least in the first phase of the pandemic, especially in Wuhan, the Chinese city where the first case of Covid-19 was recorded, the data relating to anxiety disorders among nurses directly involved in the care of patients with SARS-CoV-2 infection they were approximately 50.4\% (Lai et al., 2020; Liu et al., 2020). Surely the data relating to anxiety in the Covid-19 era are lower than those of the previous SARS pandemics (Chan et al., 2005; Chong et al., 2004; Lin et al., 2007; Lung et al., 2009), perhaps because in the previous studies the assessment of the state of anxiety among healthcare workers was carried out in the early stages of the SARS-pandemic (Zheng et al., 2020).

Moreover, in the literature it was reported how the levels of depression among healthcare workers increased with the duration of exposure to the traumatic event of maxi-emergency (Buselli et al., 2020). Although the data reported in the present study showed a significant increase in levels of depression in the second wave, these values are still not significant when compared with the Second Wave. Therefore, it was true that there was a worsening of the depressive state, but not an increase in the incidence of cases. Therefore, in this last aspect, the data shown did 
not appear to be in agreement with what was reported in the literature (Chong et al., 2004; Wu, 2009) in which there was an increase in the number of cases of depression in the face of prolonged exposure over time, while between the data reported here substantially showed a worsening of the clinical conditions among the nurses interviewed. Finally, considering the levels of insomnia, the literature highlighted how, at least in the first phase of the pandemic, there was a worsening of the conditions of insomnia among healthcare workers, in particular among nurses (Tu et al., 2020; Geoffroy et al., 2020; Wu et al., 2020) mainly due to the conditions of fear uncertainty as the workload increased, typical at the beginning of any pandemic. The data presented in this study showed no significant difference between the two epidemic waves, although there was a significant increase in the number of female nurses with insomnia disorders in the first wave. Fortunately, the present data showed a lower incidence of insomnia disorders than the incidence rates of past SARS pandemics (McAlonan et al., 2007) or other studies related to the Covid-19 pandemic (Pappa et al., 2020; Li et al., 2020). This improvement in the conditions of insomnia among nurses could be explained by the sudden health policies of implementation and adaptation to face the pandemic that each Health Company has implemented in the shortest possible time (Buselli et al., 2020; Vitale et al., 2020).

\section{The implications for research}

Literature compared anxiety, depression and insomnia disorders among nurses during the pandemic and the non-pandemic period to understand how the pandemic condition could affect the results. Instead, the present study showed the differences between the two pandemic waves, thus considering the same background condition. In this sense, this study could be considered as pilot and reliable given that the conditions were the same: the presence of the Covid-19 pandemic.

Surely further studies will be needed to understand how much the time factor and therefore, the duration of exposure to the pandemic has affected the mental health of nurses directly involved in the care of patients with Covid-19.

\section{Limitations of the study}

This study had some limitations. The sample recruited was small compared to 360.000 nurses working in Italy, of which 270.000 in the National Health System. Furthermore, the random administration of the questionnaire with the only clause if the interviewee was the assignment of Covid-19 ward could have caused selection bias in the recruitment of the sample itself. Finally, the interview carried out exclusively in online mode could have caused some biases related to the interpretation of the questionnaire itself. 


\section{Conclusion}

The data obtained showed a presence of levels of depression especially during the Second Wave and levels of Insomnia during the first wave. However, it appeared that nurses needed psychological support to better care of patients suffered from the Covid-19. Each health organizations might promote psychological support programs for their nurses in order to ameliorate the quality of the nursing assistance.

\section{References}

Ambrosi, E., Canzan, F., Di Giulio, P., Mortari, L., Palese, A., Tognoni, G., \& Saiani, L. (2020). A cura di. L'emergenza covid-19 nelle parole degli infermieri. [The covid-19 emergency in the words of the nurses]. Assistenza Infermieristica e Ricerca, 39(2), 66-108. Italian. https://doi.org/10.1702/3409.33934

Arshad Ali, S., Baloch, M., Ahmed, N., Arshad Ali, A., \& Iqbal, A. (2020). The outbreak of Coronavirus Disease 2019 (COVID-19)-An emerging global health threat. Journal of Infection and Public Health, 13(4), 644-646.

Bastien, C.H., Vallières, A., \& Morin, C.M. (2001). Validation of the Insomnia Severity Index as an outcome measure for insomnia research. Sleep Medicine, 2(4), 297-307. https://doi.org/10.1016/s1389-9457(00)00065-4.

Bohlken, J., Schomig, F., Lemke, M.R., Pumberger, M., \& Riedel-Heller, S.G. (2020). COVID-19 pandemic: stress experience of healthcare workers - a short current review. Psychiatric Praxis, 47(4), 190-197. https://doi.org/10.1055/a1159-5551.

Burton, C., Fink, P., Henningsen, P., Löwe, B., Rief, W., \& EURONET-SOMA Group. (2020). Functional somatic disorders: discussion paper for a new common classification for research and clinical use. BMC Medicine, 18(1), 34. https://doi.org/10.1186/s12916-020-1505-4.

Buselli, R., Corsi, M., Baldanzi, S., Chiumiento, M., Del Lupo, E., Dell'Osso, V., \& Carmassi, C. (2020). Professional quality of life and mental health outcomes among health care workers exposed to sars-cov-2 (covid-19). International Journal of Environmental Research and Public Health, 17(17): 6180. https://doi.org/10.3390/ijerph17176180

Buselli, R., Baldanzi, S., Corsi, M., Chiumiento, M., Del Lupo, E., Carmassi, C., Dell'Osso, L., \& Cristaudo, A. (2020). Psychological Care of Health Workers during the COVID-19 Outbreak in Italy: Preliminary Report of an Occupational Health Department (AOUP) Responsible for Monitoring Hospital Staff Condition. Sustainability, 12，5039. https://doi.org/10.3390/ su12125039

Chahoud, M., Chahine, R., Salameh, P., \& Sauleau, E.A. (2017). Reliability, factor analysis and internal consistency calculation of the Insomnia Severity Index 
(ISI) in French and in English among Lebanese adolescents. eNeurologicalSci., 7, 9-14. https://doi.org/10.1016/j.ensci.2017.03.003.

Chan, S.S., Leung, G.M., Tiwari, A.F., Salili, F., Leung, S.S., Wong, D.C., Wong, A.S., Lai, A.S., \& Lam, T.H. (2005). The impact of work-related risk on nurses during the SARS outbreak in Hong Kong. Family and Community Health, 28(3), 274-287. https://doi.org/10.1097/00003727-200507000-00008.

Che Huei, L., Ya-Wen, L., Chiu Ming, Y., Li Chen, H., Jong Yi, W., \& Ming Hung, L. (2020). Occupational health and safety hazards faced by healthcare professionals in Taiwan: A systematic review of risk factors and control strategies. SAGE Open Medicine, 8, 2050312120918999. https://doi.org/10.1177/ 2050312120918999

Cheng, V., Wong, S., Chen, J., Yip, C., Chuang, V., Tsang, O., \& Yuen, K. (2020). Escalating infection control response to the rapidly evolving epidemiology of the coronavirus disease 2019 (COVID-19) due to SARS-CoV-2 in Hong Kong. Infection Control \& Hospital Epidemiology 41(5), 493-498. https://doi.org/10.1017/ice.2020.58.

Choi, K.R., Skrine Jeffers, K., \& Cynthia Logsdon, M. (2020). Nursing and the novel coronavirus: Risks and responsibilities in a global outbreak. Journal of Advanced Nursing, 76(7), 1486-1487. https://doi.org/10.1111/jan.14369.

Chong, M.Y., Wang, W.C., Hsieh, W.C., Lee, C.Y., Chiu, N.M., Yeh, W.C., Huang, O.L., Wen, J.K., \& Chen, C.L. (2004). Psychological impact of severe acute respiratory syndrome on health workers in a tertiary hospital. The British Journal of Psychiatry, 185, 127-133. https://doi.org/10.1192/bjp.185.127

Fernandez-Mendoza, J., Rodriguez-Muñoz, A., Vela-Bueno, A., OlavarrietaBernardino, S., Calhoun, S. L., Bixler, E. O., \& Vgontzas, A. N. (2012). The Spanish version of the Insomnia Severity Index: a confirmatory factor analysis. Sleep medicine, 13(2), 207-210.

Geoffroy PA, et al. (2020). Psychological support system for hospital workers during the Covid-19 outbreak: rapid design and implementation of the Covid-Psy hotline. Front Psychiatry., 11, 511-18.

Gigli, K.H., Davis, B.S., Ervin, J., \& Kahn, J.M. (2020). Factors associated with nurses' knowledge of and perceived value in evidence-based practices. American Journal of Critical Care, 29(1), e1-e8. https://doi.org/10.4037/ ajcc2020866.

Gilbody, S., Richards, D., Brealey, S., \& Hewitt, C. (2007). Screening for depression in medical settings with the Patient Health Questionnaire (PHQ): a diagnostic meta-analysis. J Gen Intern Med., 22(11), 1596-602. https://doi.org/10.1007/ s11606-007-0333-y.

Guan, W.J., Ni, Z.Y., Hu, Y., Liang, W.H., Ou, C.Q., He, J.X., Liu, L., Shan, H., Lei, C.L., Hui, D.S.C., Du, B., Li, L.J., Zeng, G., Yuen, K.Y., Chen, R.C., Tang, C.L., Wang, T., Chen, P.Y., Xiang, J., Li, S.Y., Wang, J.L., Liang, Z.J., Peng, Y.X., Wei, L., Liu, Y., Hu, Y.H., Peng, P., Wang, J.M., Liu, J.Y., Chen, Z., Li, G., Zheng, Z.J., Qiu, S.Q., Luo, J., Ye, C.J., Zhu, S.Y., Zhong, N.S, \& China Medical Treatment Expert Group for Covid-19. Clinical Characteristics 
of Coronavirus Disease 2019 in China. The new England Journal of Medicine, 382(18), 1708-1720. https://doi.org/10.1056/NEJMoa2002032.

Hu, D., Kong, Y., Li, W., Han, Q., Zhang, X., Zhu, L.X., Wan, S.W., Liu, Z., Shen, Q., Yang, J., He, H.G., \& Zhu, J. (2020). Frontline nurses' burnout, anxiety, depression, and fear statuses and their associated factors during the COVID-19 outbreak in Wuhan, China: A large-scale cross-sectional study. EClinicalMedicine., 24, 100424. https://doi.org/10.1016/j.eclinm.2020.100424.

Huang, C.L., Wu, M.P., Ho, C.H., \& Wang, J.J. Risks of treated anxiety, depression, and insomnia among nurses: A nationwide longitudinal cohort study. PLoS One, 13(9), e0204224. https://doi.org/10.1371/journal.pone.0204224

Kertz, S., Bigda-Peyton, J., \& Bjorgvinsson, T. (2013). Validity of the Generalized Anxiety Disorder-7 Scale in an Acute Psychiatric Sample. Clin. Psychol. Psychother., 20, 456-464. https://doi.org/10.1002/cpp.1802

Kroenke, K., Spitzer, R.L., \& Williams, J.B. (2001). The PHQ-9: validity of a brief depression severity measure. Journal of General Internal Medicine, 16(9), 606-13. https://doi.org/10.1046/j.1525-1497.2001.016009606.x.

Kroenke, K. (2012). Enhancing the clinical utility of depression screening. CMAJ., 184(3), 281-2. https://doi.org/10.1503/cmaj.112004.

Laferton, J.A.C., Fischer, S., Ebert, D.D., Stenzel, N.M., \& Zimmermann, J. (2020). The Effects of Stress Beliefs on Daily Affective Stress Responses. Annals of Behavioral Medicine, 54(4), 258-267. https://doi.org/10.1093/abm/kaz046.

Lahan, V., \& Gupta, R. (2011). Translation and validation of the insomnia severity index in hindi language. Indian journal of psychological medicine, 33(2), 172-176.

Lai, J., Ma, S., Wang, Y., Cai, Z., Hu, J., Wei, N., Wu, J., Du, H., Chen, T., Li, R., et al. (2020). Factors Associated with Mental Health Outcomes Among Health Care Workers Exposed to Coronavirus Disease 2019. JAMA Netw. Open, 3, e203976.

Li, Y., Qin, Q., Sun, Q., Sanford, L. D., Vgontzas, A. N., \& Tang, X. (2020). Insomnia and psychological reactions during the COVID-19 outbreak in China. Journal of clinical sleep medicine: JCSM : official publication of the American Academy of Sleep Medicine, 16(8), 1417-1418. https://doi.org/10.5664/jcsm. 8524

Lin, C.Y., Peng, Y.C., Wu, Y.H., Chang, J., Chan, C.H., \& Yang, D.Y. (2007). The psychological effect of severe acute respiratory syndrome on emergency department staff. Emergency Medicine Journal, 24(1):12-7. https://doi.org/ 10.1136/emj.2006.035089.

Liu, C.-Y., Yang, Y.-Z., Zhang, X.-M., Xu, X., Dou, Q.-L., Zhang, W.-W., Cheng, A.S.K. (2020). The prevalence and influencing factors in anxiety in medical workers fighting COVID-19 in China: A cross-sectional survey. Epidemiol. Infect., 148, 1-17.

Lung, F.W., Lu, Y.C., Chang, Y.Y., \& Shu, B.C. (2009). Mental symptoms in different health professionals during the SARS attack: a follow-up study. Psychiatr. Q., 80 (2), 107-116. https://doi.org/10.1007/s11126-009-9095-5. 
Manea, L., Gilbody, S., \& McMillan, D. (2012). Optimal cut-off score for diagnosing depression with the Patient Health Questionnaire (PHQ-9): a meta-analysis. CMAJ, 184(3), E191-6. https://doi.org/10.1503/cmaj.110829.

Manea, L., Gilbody, S., \& McMillan, D. (2015). A diagnostic meta-analysis of the Patient Health Questionnaire-9 (PHQ-9) algorithm scoring method as a screen for depression. Gen Hosp Psychiatry., 37(1), 67-75. https://doi.org/10.1016/j. genhosppsych.2014.09.009.

McAlonan, G.M., \& et al. (2007). Immediate and sustained psychological impact of an emerging infectious disease outbreak on health care workers. Can $J$ Psychiatry., 52(4), 241-7.

Moitra, M., Rahman, M., Collins, P.Y., \& et al. (2021). Mental Health Consequences for Healthcare Workers During the COVID-19 Pandemic: A Scoping Review to Draw Lessons for LMICs. Frontiers in Psychiatry., 12: 602614. https://doi.org/10.3389/fpsyt.2021.602614.

Pappa, S., Ntella, V., Giannakas, T., Giannakoulis, V. G., Papoutsi, E., \& Katsaounou, P. (2020). Prevalence of depression, anxiety, and insomnia among healthcare workers during the COVID-19 pandemic: A systematic review and metaanalysis. Brain, behavior, and immunity, 88, 901-907. https://doi.org/10.1016/ j.bbi.2020.05.026

Patterson, P.D., Weaver, M.D., Frank, R.C., Warner, C.W., Martin-Gill, C., Guyette, F.X., Fairbanks, R.J., Hubble, M.W., Songer, T.J., Callaway, C.W., Kelsey, S.F., \& Hostler, D. (2012). Association between poor sleep, fatigue, and safety outcomes in emergency medical services providers. Prehospital Emergency Care, 16(1), 86-97. https://doi.org/10.3109/10903127.2011.616261.

Salari, N., Khazaie, H., Hosseinian-Far, A. et al. (2020). The prevalence of sleep disturbances among physicians and nurses facing the COVID-19 patients: a systematic review and meta-analysis. Global Health, 16, 92. https://doi.org/ 10.1186/s12992-020-00620-0

Spitzer, R.L., Kroenke, K., Williams, J.B., \& Löwe, B. (2006). A brief measure for assessing generalized anxiety disorder: the GAD-7. Archives of Internal Medicine, 166(10), 1092-7. https://doi.org/10.1001/archinte.166.10.1092.

Su, T.P., Lien, T.C., Yang, C.Y., Su, Y.L., Wang, J.H., Tsai, S.L., \& Y in, J.C. (2007). Prevalence of psychiatric morbidity and psychological adaptation of the nurses in a structured SARS caring unit during outbreak: a prospective and periodic assessment study in Taiwan. Journal of Psychiatric Research, 41, 119-130. https://doi.org/10.1016/j.jpsychires.2005.12.006

Tu, Z.H., He, J.W., \& Zhou, N. (2020). Sleep quality and mood symptoms in conscripted frontline nurse in Wuhan, China during COVID-19 outbreak: A cross-sectional study. Medicine (Baltimore), 99(26), e20769. https://doi.org/ 10.1097/MD.0000000000020769.

Velavan, T.P., \& Meyer, C.G. (2020). The COVID-19 epidemic. Trop Med Int Health., 25(3), 278-80.

Veqar, Z., \& Hussain, M.E. (2017). Validity and reliability of insomnia severity index and its correlation with pittsburgh sleep quality index in poor sleepers 
among Indian university students. Int $J$ Adolesc Med Health., 32(1), /j/ijamh.2020.32.issue-1/ijamh-2016-0090/ijamh-2016-0090.xml. https://doi.org/ 10.1515/ijamh-2016-0090.

Vitale, E., Cesano, E., \& Germini, F. (2020). Prevalence of Burnout among Italian Nurses: a descriptive study: Italian Nursing Burnout. Acta Biomedica, 91(4), e2020117.

Vitale, E., Moretti, B., Noternicola, A., \& Covelli, I. (2020). How the Italian Nursing students deal the pandemic Covid-19 condition. Acta Biomedica for Health Professions, 91(12-S), e2020007. https://doi.org/10.23750/abm.v91i12-S.9860.

Vitale, E., Galatola, V., \& Mea, R. (2020). Exploring within and between gender differences in burnout levels in Italian nurses engaged in the Covid-19 health emergency: a cohort observational study. Minerva Psichiatrica, 61(4), 162170. https://doi.org/10.23736/S0391-1772.20.02090-7

Vitale, E., Mea, R., Di Dio, F., Canonico, A., \& Galatola, V. (2020). Anxiety, Insomnia and Body Mass Index scores in Italian nurses engaged in the care of COVID-19 patients. Endocrine, Metabolic \& Immune Disorders Drug Targets, 20,1. https://doi.org/10.2174/1871530320666201016150033

Wang, C., Horby, P.W., Hayden, F.G., \& Gao, G.F. (2020). A novel coronavirus outbreak of global health concern. Lancet, 395(10223), 470-473. https://doi.org/10.1016/S0140-6736(20)30185-9.

World Health Organization. WHO announces COVID-19 outbreak a pandemic. Available from: http://www.euro.who.int/en/health-topics/health-emergencies/ coronavirus-covid Accessed on 3 April 2020.

$\mathrm{Wu}, \mathrm{P}$. (2009). The psychological impact of the SARS epidemic on hospital employees in China: Exposure, risk perception, and altruistic acceptance of risk. Can. J. Psychiatry, 54, 302-311.

Wu, K.L., \& Wei, X.M. (2020). Analysis of psychological and sleep status and exercise rehabilitation of front-line clinical staff in the fight against COVID19 in China. Med Sci Monit Basic Res., 26, e924085.

$\mathrm{Yu}, \mathrm{D}$. S. (2010). Insomnia Severity Index: psychometric properties with Chinese community-dwelling older people. Journal of advanced nursing, 66(10), 23502359.

Zheng, R., Zhou, Y., Fu, Y., Xiang, Q., Cheng, F., Chen, H., Xu, H., Fu, L., Wu, X., Feng, M., Ye, L., Tian, Y., Deng, R., Liu, S., Jiang, Y., Yu, C., \& Li, J. (2020). Prevalence and associated factors of depression and anxiety among nurses during the outbreak of COVID-19 in China: A cross-sectional study. International Journal of Nursing Studies, 114, 103809. https://doi.org/10.1016/ j.ijnurstu.2020.103809. 